\title{
Dentoalveolar defektli hastaların protetik rehabilitasyonunda farklı üst yapı seçenekleri: İki olgu sunumu
}

\author{
Muhammet KarcI(0000-0002-7101-822X) ${ }^{\alpha}$, Necla Demir(0000-0003-0927-6962) ${ }^{\alpha}$ \\ Selcuk Dent J, 2018; 5: 80-85 (Doi: 10.15311/selcukdentj. 321554) \\ Başvuru Tarihi: 15 Haziran 2017 \\ Yayına Kabul Tarihi: 18 Ekim 2017
}

\begin{abstract}
öz
Dentoalveolar defektli hastaların protetik rehabilitasyonunda farklı üst yapı seçenekleri: İki olgu sunumu

Dentoalveolar defektlerin oluşum nedenleri doğumsal, gelişimsel ve kazanılmış olmak üzere üç grupta toplanabilir ve hastalarda estetik, fonetik ve fonksiyonel problemlere neden olabilirler. Tedavide multidisipliner yaklaşım ve vakaya özgü bir planlama gerekmektedir. Bu olgu sunumunda dentoalveolar defekte sahip iki hastanın farklı tutucu sistemlerine sahip dental implant destekli protezler ile protetik rehabilitasyonu anlatılmaktadır.

Klinik ve radyografik muayene sonrasında hastalara implant destekli sabit protezler, diş destekli sabit protezler ve hareketli protezlerden oluşan tüm tedavi seçenekleri anlatıldı. Birinci hastada mandibular sol taraftaki defekt, CAD-CAM ile üretilen siman tutuculu kişiye özel abutmentlar kullanılarak restore edilirken; ikinci hastada maksiller sol taraftaki defekt vida tutuculu multi-unit abutmentlar kullanılarak restore edilmiştir.

Hastaların estetik ve fonksiyonel beklentileri tedavi sonrasında başarılı bir şekilde karşılanmıştır. Oral hijyen konusunda bilgilendirilen hastaların 1 haftallk kontrollerinde herhangi bir komplikasyona rastlanımamıştır ve 3 ay sonra tekrar kontrole çağrılmıştır.
\end{abstract}

\section{ANAHTAR KELIMELER}

Dentoalveolar defekt, implant üstü sabit protez, multi-unit abutment, siman tutuculu abutment

Dentoalveolar defektler, lokalizasyonları nedeniyle hastaların çoğunda estetik, fonetik ve fonksiyonel problemlere neden olur. ${ }^{1}$ Defektlerin oluşum nedenleri doğumsal, gelişimsel ve kazanılışs olmak üzere üç grupta toplanabilir. Edinsel defektlere örnek olarak travmalar (ateşli silah yaralanmaları, trafik kazaları), tümöral veya kistik oluşumların cerrahi rezeksiyonu ve enfeksiyöz hastalıklar (osteomiyelit, sifiliz) sonucunda oluşan defektler sayılabilir. Dudak-damak ve kraniyofasiyal yarıklar konjenital defektler grubuna girerken, sert ve yumuşak doku anomalileri ise gelişimsel defektlere örnek olarak gösterilebilir. ${ }^{2,3}$

Tedavi prosedürleri; acil tedavi prosedürleri, rekonstrüktif cerrahi ve protetik aşama olmak üzere üç aşamadan oluşmaktadır. ${ }^{4,5}$ Hastalar çoğu zaman çoklu

\section{ABSTRACT}

Different superstructure options in prosthetic rehabilitation of patients with dentoalveolar defects: Two case reports

Dentoalveolar defects may be caused by congenital, developmental, and acquired factors and they cause aesthetic, phonetic and functional problems in patients A multidisciplinary approach and a peculiar planning are needed in the treatment. This case report describes prosthetic rehabilitation of two patients who have dentoalveolar defects with dental implant supported prostheses with different retention systems.

After clinical and radiographical examination,the patient was informed about all treatment options, including fixed implant supported dental implants, fixed dental prosthesis and removable dentures. In the first patient, the mandibular left-sided defect was restored using a cement-retaining custom abutments produced by CAD-CAM; the second patient was treated using screw retained multi-unit abutments.

The aesthetic and functional expectations of the patients were successfully performed after the treatment. No complications were observed in the 1 week control of the patients who were informed about oral hygiene and they were recalled for control after 3 months.

\section{KEYWORDS}

Dentoalveolar defect, fixed implant prosthesis, cement retained abutment, multi-unit abutment

rekonstrüktif cerrahi aşamalarından geçmektedir. Kemik ve yumuşak doku konturları bazen normalden aşırı derece saparak hastada belirgin estetik kayıplara neden olup hastada psikolojik problemler yaratabilir. ${ }^{6}$

Dentoalveoler defekte sahip hastalarda birincil öncelik fonksiyon ve estetiği iyileştirmek olmalıdır. Buna rağmen ciddi travma veya ameliyat sonucu kazanılmış maksiller ve mandibular defektler klinisyen için büyük bir sorun oluşturmaktadır. ${ }^{7}$ Protetik tedavi ile oklüzal fonksiyon, estetik ve yumuşak doku ve kemik konturu sağlanmaktadır. ${ }^{8}$

Protetik rehabilitasyon için; hareketli bölümlü protezler, implant destekli overdenture protezler ve

\footnotetext{
${ }^{\alpha}$ Selçuk Üniversitesi Diş Hekimliği Fakültesi Protetik Diş Tedavisi AD, Konya
} 
yumuşak ve sert doku rekonstrüksiyonu prosedürlerinden sonra konvansiyonel veya implant destekli sabit protezler gibi çeşitli tedavi seçenekleri bulunmaktadır. Dental implant destekli protezler birçok vakada en rahat ve güvenilir tedavi seçeneğidir. İşlevsel ve estetik açıdan daha az tatmin edici olan hareketli protezlere oranla oral rehabilitasyon ile ilgili problemlerin üstesinden daha iyi gelebilmektedir. ${ }^{9-11} \mathrm{Bu}$ tedavi seçeneği ayn zamanda protez stabilitesini arttırarak büyük maksillofasiyal defektlere sahip hastalarda tutuculuğu ve kas fonksiyonlarını iyileştirir. ${ }^{12}$

Implant destekli protezlerde, siman tutuculu veya vida tutuculu üst yapı restorasyon tasarımlarının, tutucu mekanizmaları birbirinden farklıdır ve estetik, tutuculuk, pasif oturum, maliyet, oklüzyon, restorasyonun yenilenebilirliği ve komplikasyon gibi konularda birbirlerine göre avantaj ve dezavantajlara sahiptirler. Tutucu mekanizmaların oklüzal tasarım ve kuvvet iletimine direkt etkisi vardır. Planlama aşamasında hangi tutucu sisteminin kullanılacağına karar verilmelidir. ${ }^{13}$

$\mathrm{Bu}$ olgu sunumunda kazanılmış dentoalveolar defekte sahip iki hastanın dental implant destekli protezler ile protetik rehabilitasyonu anlatımaktadır. Birinci hastada mandibular sol taraftaki defekt, CAD-CAM ile üretilen siman tutuculu kişiye özel abutmentlar kullanılarak restore edilirken; ikinci hastada maksiller sol taraftaki defekt vida tutuculu multi unit abutmentlar kullanılarak restore edilmiştir.

\section{OLGU SUNUMU}

\section{OLGU 1}

Sol mandibular anterior bölgesinde travma hikayesi olan 25 yaşındaki bayan hasta protetik rehabilitasyon için Selçuk Üniversitesi Diş Hekimliği Fakültesi Protetik Diş Tedavisi Anabilim Dalı'na başvurmuştur. Klinik ve radyolojik muayenesi sonucunda 32,33 ve 34 numaralı dişlerin olmadığı ve ilgili bölgede alveolar krette defekt olduğu tespit edilmiştir. Hastaya implant destekli sabit protezler, diş destekli sabit protezler ve hareketli protezlerden oluşan tüm tedavi seçenekleri anlatıldı. Hastanın yaşının genç olmasından dolayı hareketli protez kullanmada ve diş destekli sabit bir protezde olası diş preparasyonu konusunda isteksiz olması nedeniyle defektli bölgenin implant destekli bir protezle daha fonksiyonel restore edileceği kanaatine varılmıştır.

Defektli bölgenin varlığından dolayı 32 numaralı diş bölgesine implant yerleştirilememiştir. 33 ve 34 numaralı diş bölgelerine kemik augmentasyonu yapılmadan $12 \mathrm{~mm}$ uzunluğunda ve $3.3 \mathrm{~mm}$ çapında 2 adet implant yerleştirilmiş (Straumann, Waldenburg,
Switzerland) ve osseointegrasyonun gerçekleşmesi için 3 ay beklenmiştir (Resim 1). Dönüşümsüz hidrokolloidal materyalle (Alginmax, Major Dental, Moncalieri, Italy) alınan anatomik ölçülerden elde edilen alt ve üst çene tanı modelleri, hastadan alınan çeneler arası kayıtlara göre yarı ayarlanabilir bir artikülatöre (Hanau Wide-Vue II, Buffalo, NY) bağlanmış ve hastanın oklüzal durumu laboratuvarda analiz edilmiştir. Yapılan analiz sonucunda hastanın defektli bölgenin kret tepesi ile antagonist dental ark arasındaki interoklüzal mesafenin $2 \mathrm{~cm}$ olduğu saptanmıştır. Bu bölgedeki implant destekli protezin standart bir abutment kullanılarak yapılması interoklüzal mesafeden dolayı uygun olmayacağı için, CAD-CAM ile üretilen kişiye özel abutmentlar yapılmasına karar verilmiştir.

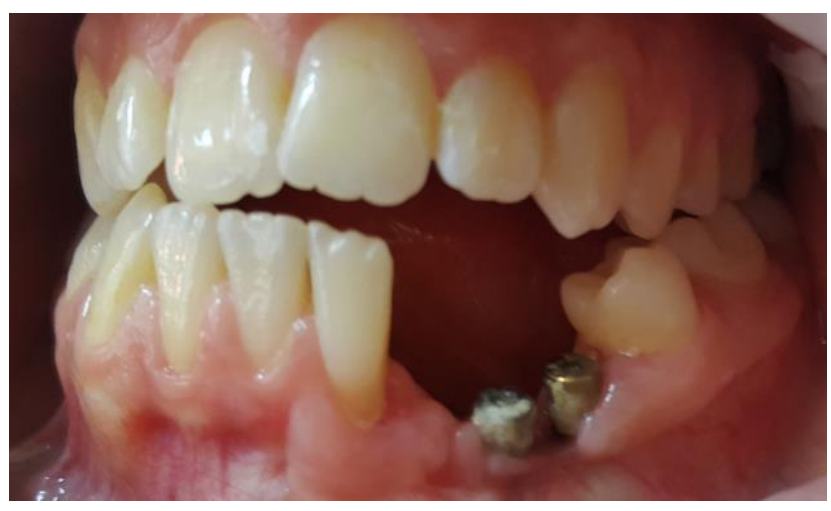

Resim 1.

Tedavi öncesi ağız içi görünüm

Sisteme ait ölçü postları implantlara fikse edildikten sonra çift karıştırma tekniği ve kapalı kaşık ölçü yöntemi ile polivinilsiloksan ölçü maddesi (Reprosil, Dentsply, Austuria) kullanılarak ölçü alındı (Resim 2). Sertleşme sonrası kaşık ağızdan çıkarılarak implant analogları ölçü postlarına fikse edildi. Elde edilen alçı model kişisel abutment yapımı için implant firmasının laboratuarına gönderilmiştir. Gelen abutment ağız içinde prova edildi ve metal at yapının dökümü için tekrar laboratuvara göderildi (Resim 3). Metal ve dentin provalar yapıldı. (Resim 4). Abutmentlar implantlara $35 \mathrm{~N} / \mathrm{cm}$ tork kuvveti ile fikse edildi. Oklüzal ilişkiler son kez kontrol edildi ve son olarak restorasyonlar çinko polikarboksilat esaslı siman (Adhesor Carbofine Spofe Dental, Czech Republic ) ile simante edildi (Resim 5). Hastanın fonksiyonel ihtiyaçları karşılandı ve estetik olarak tatminkar bir sonuç elde edildi. Gerekli oral hijyen motivasyonu verildikten sonra hasta 1 hafta sonra kontrole çağrılmıştır. Herhangi bir komplikasyon tespit edilmemiş ve hasta 3 ay sonra ikinci kontrole çağrılmıştır. 


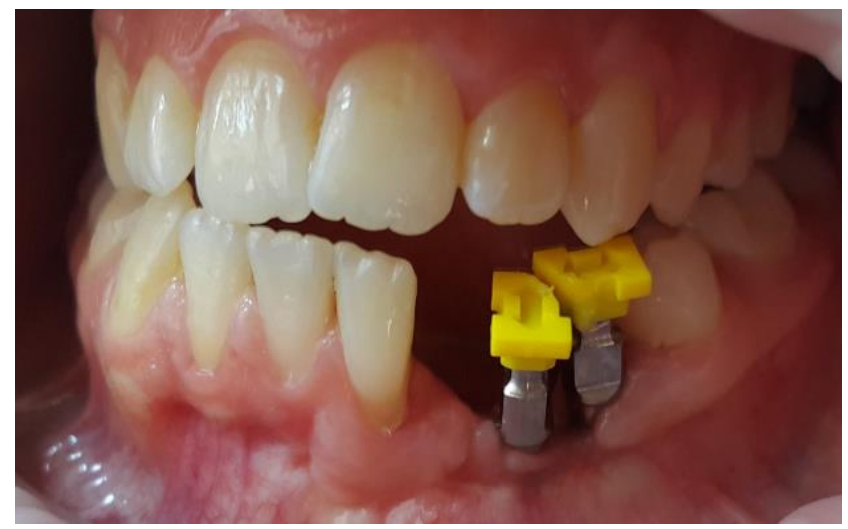

Resim 2.

Ölçü parçalarının ağız içi görünümü

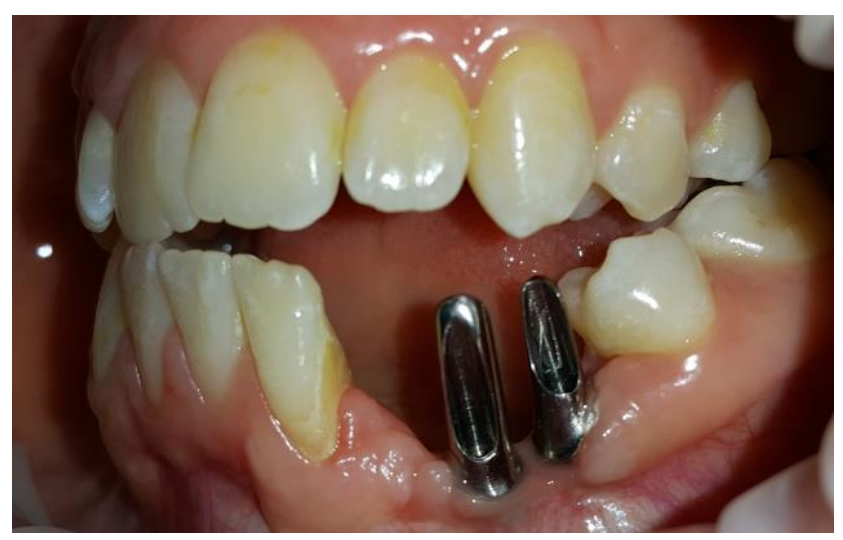

Resim 3.

Kişisel abutmentların provası

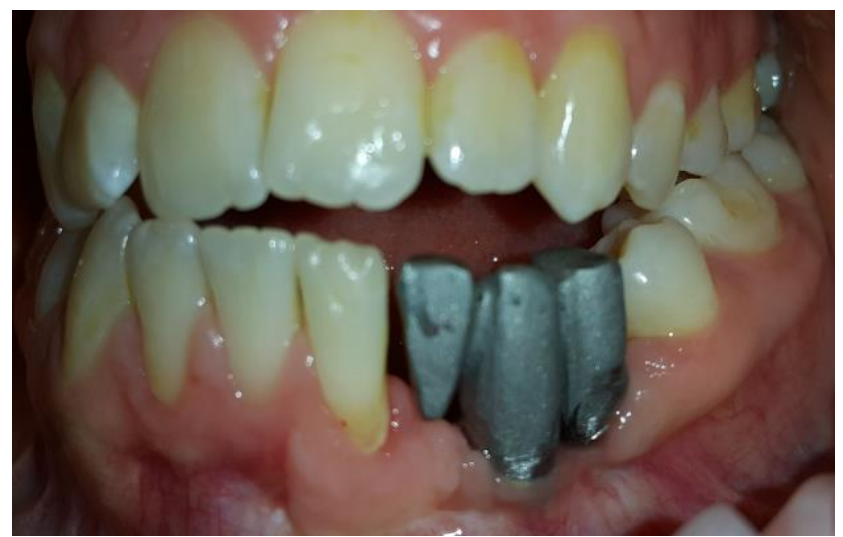

Resim 4.

Metal prova

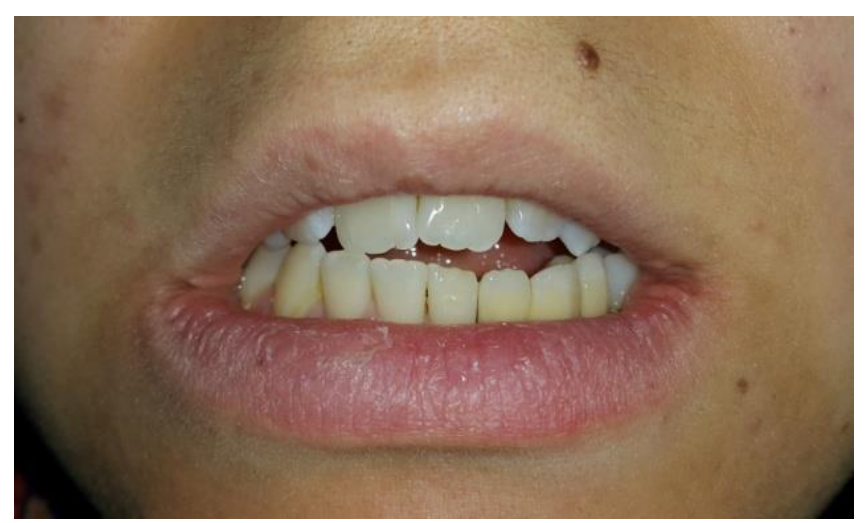

Resim 5 .

Final görünüm

\section{OLGU 2}

Sol maksiller bölgesinde kemik kaybı ile kliniğimize başvuran 45 yaşındaki erkek hastanın klinik ve radyolojik muayenesi yapıldı. Hastadan alınan anamnezde ilgili bölgedeki dişlerin kaybıyla beraber gömülü kanin dişin çekimiyle bölgede kemik kaybı olduğu öğrenilmiştir. Hastaya farklı tedavi seçenekleri anlatıldı (implant destekli sabit protezler, diş destekli sabit protezler ve hareketli protezler). Hastanın diş preparasyonu konusunda isteksiz olması ve maddi durumunun iyi olmasından dolayı implant destekli sabit bir protez yapılmasına karar verilmiştir. 27 numaralı dişindeki eski kron restorasyonun da yenilenmesine karar verilmiştir.

23, 24 numaralı diş bölgelerine $11.5 \mathrm{~mm}$ uzunluğunda ve 3.75 çapında 2 implant, 26 numaralı diş bölgesine $11.5 \mathrm{~mm}$ uzunluğunda $5 \mathrm{~mm}$ çapında 1 implant olmak üzere toplam üç implant (MIS-Implants Inc., Shlomi, Israel) yerleştirilmiştir (Resim 6). Hastanın ileri cerrahi tedavi yaklaşımlarını reddetmesinden dolayı mevcut kemik desteğine göre uygun olan bölgelere implantlar yerleştirilmiştir. Özellikle 23 ve 24 numaralı implantlar bölgesinde interoklüzal mesafenin fazla olmasından ve implantların diş eti seviyesinden fazla aşağıda olmasından dolayı üst yapının vida tutuculu bir restorasyon yapılmasına karar verilmiştir.

Uygun tedavi seçeneği belirlendikten sonra ölçü alımı safhasına geçildi. Sisteme ait ölçü parçaları ağıza yerleştirildikten sonra polivinilsiloksan ölçü maddesi (Reprosil, Dentsply, Austuria) kullanılarak ölçü alındı (Resim 7). Laboratuvara gönderilen alçı modelde 4 $\mathrm{mm}$ diş eti yüksekliğine sahip sisteme ait multi-unit abutmentlar seçilmiştir (Resim 8). Multi-unit abutmentlarla uyumlu plastik parça kullanılarak metal altyapının dökümü yapılmıştır. Metal alt yapı ağıza transfer edilmiş ve metal altyapının provası gerçekleştirilmiştir (Resim 9). 27 numaralı dişin metal 
altyapısının da provası yapıldıktan sonra metal altyapılar veneer porselenin işlenmesi için tekrar laboratuvara gönderildi. İlgili bölgedeki sert ve yumuşak doku kaybını estetik olarak tolere edebilmek için metal altyapının servikal bölgesinde pembe porselen kullanılarak ideal kron oranları elde edilmeye çalışıldı. Restorasyonlar ağız içerisinde marjinal uyum, internal adaptasyon, oklüzal kontaktlar, oklüzyon ve artikülasyon açısından değerlendirilerek gerekli uyumlamalar yapıldı. Glazürleme işlemi yapılarak restorasyonlar bitirildi (Resim 10). Bitmiş restorasyonun ağıza yerleştirilmesi sırasında önce multi-unit abutmentlar üretici talimatlarına göre $35 \mathrm{Ncm}$ tork ile implantlara sabitlendi. Metal destekli porselen sabit restorasyon da yine üretici talimatlarına göre 30 Ncm ile multi-unit abutmenta fiske edildi. 27 numaralı diş üzerindeki veneer kron da çinko polikarboksilat siman (Adhesor Carbofine, Spofa Dental, Almanya) kullanılarak simante edildi. Hasta protezin bakımı ile ilgili bilgilendirildi ve ağız sağlığı konusunda motive edildi.

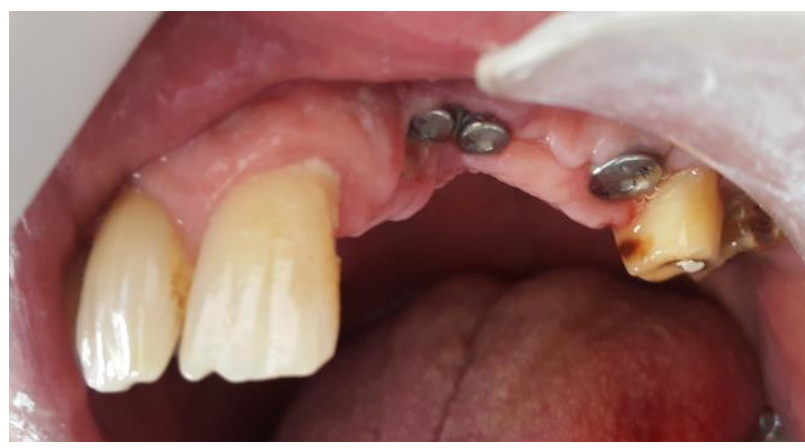

Resim 6.

Tedavi öncesi ağız içi görünüm

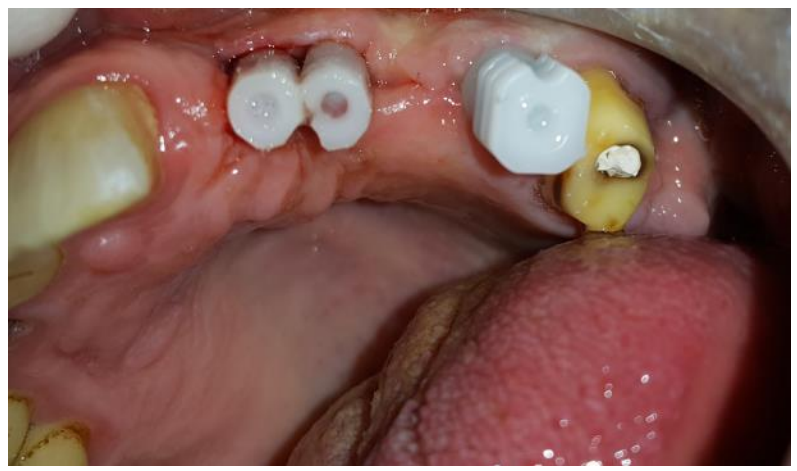

Resim 7.

Ölçü parçalarının ağız içi görünümü

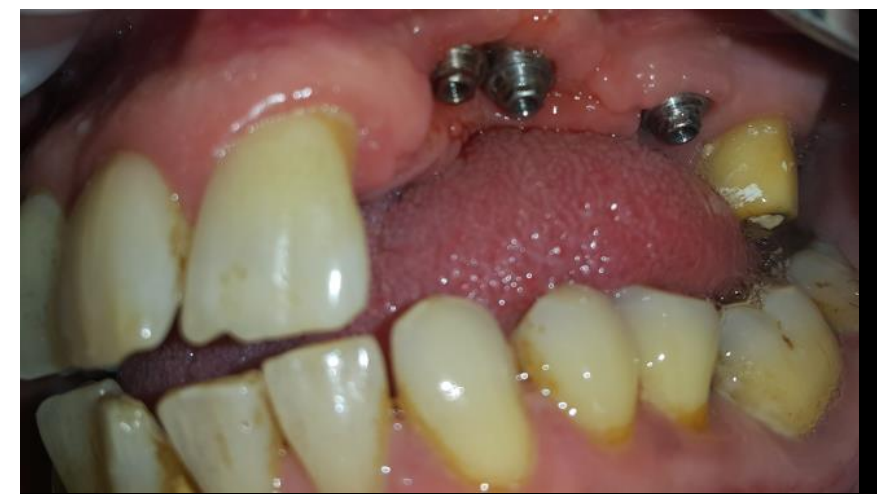

Resim 8.

Multi-unit abutmentların ağızda kontrolü

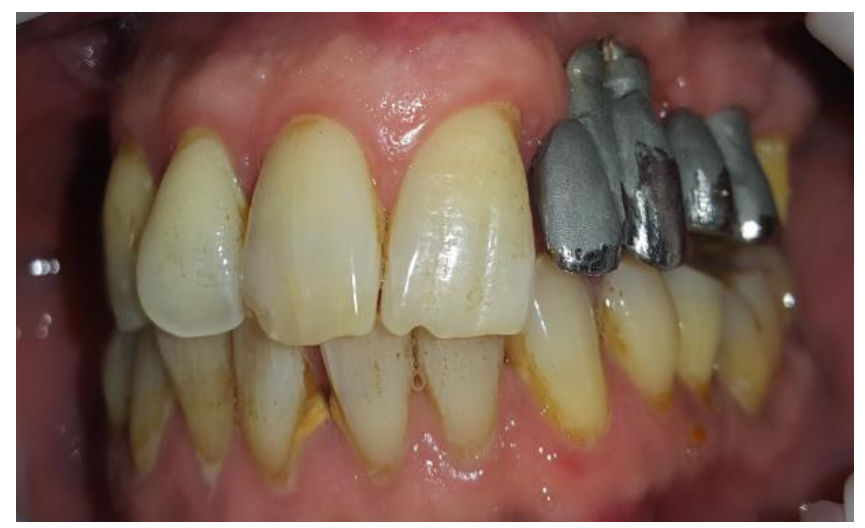

Resim 9.

Metal prova

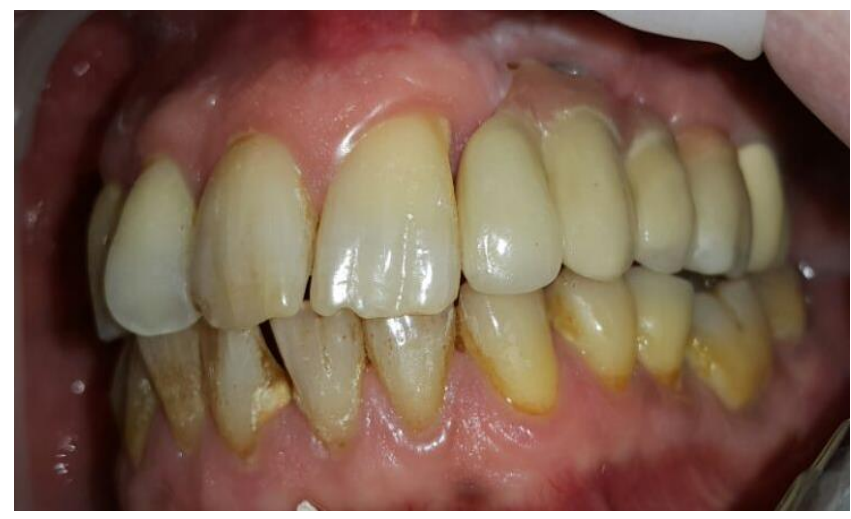

Resim 10.

Final görünüm

\section{TARTIŞMA}

Ciddi travma veya ameliyatlar sonucu kazanılan maksiller ve mandibular defektler klinisyen için büyük bir zorluk teşkil etmektedir. Hastalar için fonksiyon ve fonasyonda ciddi problemler görülebilir. Dentoalveolar defektlerdeki protetik rehabilitasyonun 
hedefleri, estetik hedeflerin yanı sıra fonksiyonel rehabilitasyon ve psikolojik terapidir. Yumuşak doku ve sert doku defekti olan hastalar özel olarak değerlendirilmeli ve tedavi planlaması sırasında dikkatli olunmalıdır.

$\mathrm{Bu}$ hastalar için, geleneksel hareketli protezler, implant destekli hareketli protezler ve diş ve/veya implant destekli sabit protezler olmak üzere farkl protez tedavi seçenekleri bulunmaktadır. ${ }^{14}$ Dental implantlar, protetik rehabilitasyon için destek sağlar ve alveolar kemik hacmini korur. ${ }^{15}$ İmplantların uzun süreli sağkalım ve başarı oranları, implant destekli protezlerin prognozunu arttırmaktadır. İmplant destekli hareketli ve sabit protezler, çene rezeksiyonu ve rekonstrüksiyonu sonrasında kusurları olan hastalar için uygun bir tedavi seçeneği olduğu gösterilmiştir. ${ }^{16}$ İmplant üstü protezler, konvansiyonel protezler ile kıyaslandığında stabilite, retansiyon, çiğneme kuvveti ve çiğneme verimliliği ve psikolojik etkisi bakımından önemli ölçüde avantajlıdır. ${ }^{17}$

Implant destekli sabit protezlerde kullanılan daimi abutmentlar, final restorasyonu için kullanılırlar ve kesin olarak yerlerinde kalırlar. Bu abutmentlar, standart abutment (simante veya vidalı), dökülebilir kişiye özel abutment (simante veya vidalı) ya da bilgisayar üretimi kişiye özel abutment (simante veya vidalı) olarak üç ana başlık altında toplanabilir. Seçim; klinik vaka, klinisyenin tecrübesi ve hastanın tercihine göre değişebilir. ${ }^{18}$ Önceden hazırlanmış abutmentlar olan standart abutmentlar çoğu titanyumdan yapılır. Standart abutmentlar genelde abutment ve abutmenttan ayrı olarak titanyum veya altın alaşımından yapılmış bir vida olmak üzere iki parçadan oluşur. ${ }^{19}$

Yetersiz interoklüzal mesafe, 15 dereceden fazla açılanma problemleri ve implant üreticisinin en fazla boyun yüksekliğine sahip abutmentından en az $1 \mathrm{~mm}$ daha yüksek boyun yüksekliğine sahip abutment gerektiren durumlarda ideal bir profil yakalamak için kişiye özel abutmentlar kullanılabilir. Ayrıca dişlerin ve yumuşak dokunun orjinal kesitsel profillerinin taklit edilmesini gerektiren durumlar, 3 ya da daha fazla implantın splinte edilmesini gerektiren vakalar ve interproksimal aralığın hijyen sağlanması bakımından yeterli olmadığı vakalar kişiye özel abutment kullanımının gerekli olduğu diğer durumlar olarak sayılabilir. Kişiye özel abutmentların yapımında titanyum veya seramik kullanılabilmektedir. ${ }^{20}$

Implant destekli protezlerde, siman tutuculu veya vida tutuculu üst yapı restorasyon tasarımları kullanılmaktadır. Siman tutuculu protezlerde oklüzal delik olmadığından daha estetik görünümdedir. ${ }^{21}$ Aradaki siman tabakasından dolayı daha pasif bir oturum sağlanabilir. ${ }^{22}$ Ayrıca simante restorasyonların kullanıldığı seramik kaplamalarda daha iyi bir kırılma direnci görülmüştür. ${ }^{23}$ Ancak bu avantajlarının yanında, protezin çıkarılmasının zor olması ve yeterli tutuculuğu sağlayabilmek için daha uzun abutmentlara intiyaç duyulması gibi dezavantajlara sahiptir. Ayrıca simantasyon prosedürlerinden sonra artık simanın uzaklaştırılamamasından dolayı mukosit ve peri-implantitis gibi yumuşak doku komplikasyonlarının görülme riski daha fazla olmaktadır. ${ }^{24}$ Siman tutuculu abutmentlar, farklı implant pozisyonlarına daha kolay uyum sağlar ve daha geniş kullanım alanına sahip olduğu söylenebilir. ${ }^{21}$

Vida tutuculu implant destekli protezler ise siman tutuculu implant destekli protezlere kıyasla; yerinden çıkarılması tekrar yerleştirilmesinin (retrievability) daha kolay olması, kısıtlı $(<4 \mathrm{~mm}$ ) veya artmış interoklüzal mesafe durumunda daha verimli olması ve geçici restorasyon ile daha iyi doku cevabı alınması gibi avantajlara sahiptir. ${ }^{25}$ Vida tutuculu protezlerde vida giriş yolunun bukkal veya lingualde bulunması estetik sebeplerden dolayı tercih edilmektedir ancak bunun sağlanamadığı vakalarda vida giriş yolu bukkalde de bulunabilir. Bu durum hem başlangıç aşamasında hem de restorasyonun üst yapısında yapılacak olan bir düzeltme sonrasında vida giriş yolunun kapatılması sırasında estetik problem oluşturur. Ayrıca vida boşluğunun posterior dişlerde santral fossaya denk gelmesi de oklüzal problemlere yol açabilir. Çünkü bazı vakalarda vida boşluğunu ağzı oklüzal yüzün yarısını kaplayabilmektedir. ${ }^{21}$

Planlama aşamasında tedavi seçeneklerinin sahip olduğu bütün avantaj ve dezavantajlar vaka özelinde değerlendirilerek uygun tedavi seçeneğinin belirlenmesinin tedavideki en önemli aşama olduğu unutulmamalıdır.

\section{SONUÇ}

İmplant diş hekimliğindeki gelişmelerle birlikte dentoalveolar defektli hastaların tedavisinde implant destekli protezlerin kullanımı ve başarı oranı artmaktadır. Bu tür hastalarda yumuşak ve sert dokudaki kayıplara bağlı olarak standart abutmentların yerine kişiye özel abutmentların kullanımı daha iyi bir seçenek olabilir. Kişiye özel abutmentlar siman tutuculu veya vida tutuculu olmak üzere iki tipte kullanılabilmektedir. Bu vaka raporu mandibular ve maksiler dentoalveolar defekti olan 2 hastanın siman tutuculu ve vida tutuculu kişiye özel abutmentlar kullanılarak implant destekli sabit protezler ile rehabilitasyonu anlatılmaktadır. Her iki hastada da estetik, fonksiyon ve fonasyon açısından hasta memnuniyeti sağlanmıştır. Hastaların bir hafta sonraki kontrollerinde gingival, estetik veya fonsiyonel herhangi bir probleme rastlanmadı ve 3 ay sonra tekrar kontrole çağrıldı. 


\section{KAYNAKLAR}

1. Atay A, Günay $Y$. Çene-yüz protezlerinde bakım. Atatürk Üniv Diş Hek Fak Derg 2007; 2: 22-25.

2. Çötert HS. Çene-Yüz Protezleri, İzmir: Ege Üniversitesi Basımevi, 2003.

3. Thomas KF. Prosthetic Rehabilitation, London: Quintessence Publishing Co, 1994.

4. Vinzenz K, Schaudy C, Würinger E. The iliac prefabricated composite graft for dentoalveolar reconstruction: a clinical procedure. Int $\mathrm{J}$ Oral \& Maxillofac Imp 2005; 21(1): 117-23.

5. Gruss JS. Complex craniomaxillofacial trauma: evolving concepts in management. J Trauma Acute Care Surg 1990; 30(4): 377-83.

6. Branemark R, Branemark PI. Osseointegration in skeletal reconstruction and rehabilitation: a review. J Rehab Res Develop 2001; 38(2): 175-82.

7. Besir Kalayci B, Kilic S, Altintas SH. Prosthetic rehabilitation of a patient with iliac graft after mandibulectomy and partial glossectomy. HealthMED 2013; 7: 1409-13.

8. Sarukawa S, Noguchi T, Ohiwa I. Bare bone graft with vascularised iliac crest for mandibular reconstruction. J Craniomaxillofac Surg 2012; 40: 616.

9. Buser D, Mericske-Stern R, Bernard JP. Long-term evaluation of non-submerged ITI implants. Clin Oral Implants Res 1997; 8: 161-72.

10.Zarb GA, Schmitt A. The longitudinal clinical effectiveness of osseointegrated dental implants: the Toronto study. Part III: problems and complications encountered. J Prosthet Dent 1990; 64: 185-94.

11.Zarb GA, Schmitt A. The longitudinal clinical effectiveness of osseointegrated dental implants: the Toronto Study. Part II: the prosthetic results. J Prosthet Dent 1990; 64: 53-61.

12. Cakan U, Anil N, Aslan Y. Prosthetic rehabilitation of a mandibular gunshot defect with an implantsupported fixed partial denture: a clinical report. J Prosthet Dent 2006; 95: 274-9.

13.Jorgensen KD. The relationship between reten $\neg$ tion and convergence angle in cemented veneer crowns. Acta Odontol Scand 1955; 13(1): 35-40.

14.Bidra AS, Veeranki AN. Surgical and prosthodontic reconstruction of a gunshot injury of the mandible using dental implants and an acrylic resin fixed prosthesis: a clinical report. J Prosthet Dent 2010; 104: 142- 8.

15. Jemt T. Single implants in the anterior maxilla after 15 years of follow-up: comparison with central implants in the edentulous maxilla. Int $\mathrm{J}$ Prosthodont 2008; 21 : 400-8.

16. Oelgiesser D, Levin L, Barak S. Rehabilitation of an irradiated mandible after mandibular resection using implant/tooth-supported fixed prosthesis: a clinical report. J Prosthet Dent 2004; 94: 310-4.
17.Preciado A, Del Rio J, Lynch CD. A new, short, specific questionnaire (QoLIP-10) for evaluating the oral health-related quality of life of implantretained overdenture and hybrid prosthesis wearers. J Dent 2013; 41: 753-63.

18.Terzioğlu H, Öztürk B. İmplant-Abutment Özelliklerinin Tedavinin Başarısındaki Etkisi. Turkiye Klinikleri J Prosthodont-Special Topics 2015; 1(2): 23-29.

19.Palmer RM, Smith BJ, Howe LC, Palmer PJ. Implants in clinical dentistry. Martin Dunitz Ltd; 2005. p. 132-46.

20.Karunagara S, Paprocki GJ, Wicks R, Markose S. A rewiew of implant abutments - abutment classification to aid prosthetic selection. J Tenn Dent Assoc 2013; 93(2): 18-24.

21.Üçtaşlı S. İmplant Üstü Vida-Tutuculu veya Siman-Tutuculu Protetik Restorasyonlar: Güncel Yaklaşımlar. Turkiye Klinikleri J ProsthodontSpecial Topics 2015; 1(2) :53-9.

22. Hebel KS, Gajjar RC. Cement-retained versus screw-retained implant restorations: achieving optimal occlusion and esthetics in implant dentistry. J Prosthet Dent 1997; 77: 28-35.

23.Sahin S, Cehreli MC. The significance of passive framework fit in implant prosthodontics: Current status. Implant Dent 2001; 10: 85-92.

24.Torrado E, Ercoli C, Al Mardini M, Graser GN, Tallents $\mathrm{RH}$, Cordaro L. A comparison of the porcelain fracture resistance of screw-retained and cemented-retained implant-supported metal-ceramic crowns. J Prosthet Dent 2004; 91: 532-7.

25. Wilson TG. The positive relationship between excess cement and peri-implant disease: a prospective clinical endoscopic study. J Periodontol 2009; 80: 1388-92.

Yazışma Adresi:

Muhammmet KARCI

Selçuk Üniversitesi Diş Hekimliği Fakültesi

Protetik Diş Tedavisi AD

Konya, Türkiye

Tel : +90 $3322410041 / 1186$

Faks : +90332 2410062

E-Mail: muhammetdt48@hotmail.com 